PROLOGUE

\title{
Documenting a Life
}

It is our inward journey that leads us through time-forward or back, seldom in a straight line, most often spiraling. Each of us is moving, changing.... As we discover, we remember; remembering, we discover.

EUDORA WELTY, ONE WRITER'S BEGINNINGS

THIS MEMOIR LOOKS BACK over twenty-some years of life experience. It encompasses times of joyous discovery and hopeful anticipation, times of loss and sadness and anger. But memory is a shape-shifter and a deceiver, capable of altering our view of all past realities into a cleverly crafted perception that fits with our present view of self-in-world. Memory conceals, invents, flatters. Memory makes mythology. You can't trust memory to tell the truth. I can't, anyway.

What made this memoir possible was not memory, that notoriously unreliable beast, but my habit of keeping a daily journal, or at least a daily diary, when there wasn't time for serious, introspective writing. I've held on to these notebooks and computer files, resisting the occasional temptation, in a fit of housekeeping tidiness, to chuck the whole lot of them into the rubbish. There's certainly a lot of trash in those pages - whines, complaints, angry rants, mindless raves, the effluvium of life caught on the fly. But there's good stuff there, too. People and events I've forgotten, feelings I've hidden, patterns I couldn't see then but that would emerge with time, details that slipped through the cracks of the floor of my mind and into the cellar where unremembered things lie, dark, dust-covered, silent.

The journal has been my traveling companion as I've backtracked along the trail of the last couple of decades. Because it's there to read and refer to, I've had to deal only with the distortions of the present point of view (that is, the present of the journal, in whatever year it was written), rather than the inevitable distortions I'd see if I looked into the past through the unreliable mirrors of 
memory. I can't lay claim to absolute truth, of course, any more than you can, when you tell your own story. But I will lay claim to the relative truths of my perceptions, while I candidly admit to their selectivity, slanting, inexactness, and incompleteness.

I've journaled since I was in graduate school at Berkeley in the late 1960s. Oh, those years, chaotic, cataclysmic, incoherent-a single mother with three young kids, Peace Park up the hill, Haight-Ashbury across the Bay, a dissertation in the typewriter. These were the years of the Flower Children and antiwar protests and Kent State, and all that tumultuous energy lives still in my journal. Sometimes I wrote regularly, sometimes intermittently, but more regularly and more obsessively as the years went along. Each year, on my birthday, I made it a practice to reread and annotate what I wrote during the previous year; every few years, I'd pick a period to revisit and spend a day or so rereading several years' worth of journals. I have never failed to be astonished, or enlightened, or amused, or perturbed, or embarrassed. And I have never failed to learn something new about myself, something I didn't already know, or something I knew once and had forgotten.

As I wrote this memoir, I read through a cache of sixteen thick handwritten notebooks and more than five hundred single-spaced pages of computer printout, covering the years between 1985 and 2006. I've included some of the entries in this memoir - not because they are especially well written or describe some momentous event, but because they are typical in their every-daily-ness. And because they help to frame my story in the context of what really happened.

The journal has lived through several incarnations, from notebook to computer and now (at least in part) to cyberspace. I first kept my blog, Lifescapes, on my Web site, then moved to first one blog host and then another, looking for the right home. I'm now settled at www.susanalbert.typepad.com/lifescapes. There, you'll meet my public self, the self I like to present to the world. For the private self, you'd have to dig into the notebooks I still keep.

Together, these public and private explorations are as reliable a record of my past lives and invented selves as I am ever likely to have. 
TOGETHER, ALONE 
THIS PAGE INTENTIONALLY LEFT BLANK 